\title{
Serum thyroid hormone reference intervals in the apparently healthy individuals of Zhengzhou area of China
}

P. Wang ${ }^{1}$, Y.J. Gao ${ }^{1}$, J. Cheng ${ }^{1}$, G.L. Kong ${ }^{1}$, Y. Wang ${ }^{1}$, X.Y. Wu ${ }^{1}$, Z.G. Zhao ${ }^{2}$ and H.J. Yuan ${ }^{2}$

${ }^{1}$ Department of Nuclear Medicine, People's Hospital of Zhengzhou University, Zhengzhou, China

${ }^{2}$ Department of Endocrinology, Henan Provincial People's Hospital, Zhengzhou, Henan, China

Corresponding author: Y.J. Gao

E-mail: gyongju@163.com

Genet. Mol. Res. 13 (3): 7275-7281 (2014)

Received June 10, 2013

Accepted October 4, 2013

Published April 11, 2014

DOI http://dx.doi.org/10.4238/2014.April.14.15

\begin{abstract}
This study aimed to establish reference intervals for serum thyroid hormones [serum thyroid-stimulating hormone (TSH), triiodothyronine $\left(\mathrm{TT}_{3}\right)$, thyroxine $\left(\mathrm{TT}_{4}\right)$, free triiodothyronine $\left(\mathrm{FT}_{3}\right)$, and free thyroxine $\left.\left(\mathrm{FT}_{4}\right)\right]$ in apparently healthy individuals living in Zhengzhou. According to the requirement for laboratory support for the diagnosis and monitoring of thyroid diseases in the National Academy of Clinical Biochemistry (NACB) laboratory medicine practice guidelines, a total of 211 apparently healthy individuals were enrolled (94 men, 117 women, 2377 years old) from Zhengzhou for measurement of serum levels of TSH, $\mathrm{TT}_{3}$, $\mathrm{TT}_{4}, \mathrm{FT}_{3}$, and $\mathrm{FT}_{4}$ by using the Siemens ADVIA Centaur XP analyzer. All markers were analyzed across gender- and age-specific groups by using the $t$-test and ANOVA. The reference intervals of all markers were determined by $P_{2.5}-P_{97.5}$. We detected gender-associated statistical significances for $\mathrm{TT}_{3}$, $\mathrm{TT}_{4}, \mathrm{FT}_{3}$, and $\mathrm{FT}_{4}(t=3.299,2.141,5.868,5.358 ; \mathrm{P}<0.05)$, but not for TSH $(t=-1.776, \mathrm{P}>0.05)$. Correlation analysis showed that all markers were
\end{abstract}


negatively correlated with age $(\mathrm{P}>0.05)$. The new reference intervals for $\mathrm{TT}_{3}, \mathrm{TT}_{4}, \mathrm{FT}_{3}, \mathrm{FT}_{4}$, and $\mathrm{TSH}$ were established: $0.76-1.38 \mathrm{ng} / \mathrm{mL}, 5.96-11.27$ $\mu \mathrm{g} / \mathrm{dL}, 3.88-5.59 \mathrm{pM}, 11.69-18.84 \mathrm{pM}, 0.89-5.93 \mu \mathrm{IU} / \mathrm{mL}$, respectively. In conclusion, we added a new database of reference intervals of the serum thyroid hormones for the Chinese adult population.

Key words: Apparently healthy individuals; Thyroid hormones; Reference intervals; NACB

\section{INTRODUCTION}

The serum thyroid-stimulating hormone (TSH), triiodothyronine $\left(\mathrm{TT}_{3}\right)$, thyroxine $\left(\mathrm{TT}_{4}\right)$, free triiodothyronine $\left(\mathrm{FT}_{3}\right)$, and free thyroxine $\left(\mathrm{FT}_{4}\right)$ are the most useful biomarkers in the clinical diagnosis for thyroid dysfunction, especially for subclinical thyroid disease (Dayan, 2001; Surks et al., 2004). Reference intervals are indispensable in evaluating laboratory test results. Establishing correct reference intervals is an important task for a clinical laboratory. Most of the European learned societies for clinical chemistry have concluded that each clinical laboratory should produce its own reference values (Jones and Barker, 2008). However, most clinical laboratories used the reference intervals provided by the manufacturer or those reported in the available literature, which may not match the clinical results obtained for local populations. Some authors have reported the thyroid hormone reference intervals for Chinese populations (Quinn et al., 2009; Chan et al., 2011).

In our laboratory, nearly 80,000 serum thyroid hormone tests are performed using the Siemens ADVIA Centaur XP analyzer every year. Therefore, it is very important for us to establish the thyroid hormone reference intervals appropriate for the population served by our laboratory. The aim of this study is to set up the thyroid hormone reference intervals for Zhengzhou according to the National Academy of Clinical Biochemistry (NACB) laboratory medicine practice guidelines (Baloch et al., 2003).

\section{MATERIAL AND METHODS}

\section{Subjects}

A total of 211 apparently healthy individuals living in iodine-adequate area from Zhengzhou ( $\mathrm{N}=211,94$ men and 117 women, aged from 23 to 77 years) were selected from the healthy individuals who visited our physical examination center in October 2012. The subjects were selected based on the criteria recommended by the NACB: 1) no detectable thyroid autoantibodies, thyroid peroxidase antibody (TPOAb) or thyroglobulin antibody (TgAb); 2) no personal or family history of thyroid dysfunction; 3 ) normal thyroid ultrasound (no visible goiter and abnormal echo); 4) no severe heart, lung, or endocrine diseases; 5) no medications such as phenytoin or glucocorticoids taken that can affect the detection of thyroid hormone; 6) no pregnancy. All subjects signed the informed consent.

\section{Methods}

Blood samples were collected from the cubital vein of subjects fasting for more than 
$8 \mathrm{~h}$ in the morning. All specimens were measured within $8 \mathrm{~h}$ by using the ADVIA Centaur XP analyzer (Siemens Healthcare Diagnostics, Germany). Internal quality control products were purchased from BIO-RAD Laboratories, Inc. (USA, Lot: 40250).

\section{Accuracy test}

Internal quality control was performed daily by using random samples at 3 levels. The mean and standard deviation of the data were calculated and then compared with the fresh data from BIO-RAD.

\section{Precision test}

Mixed serum samples were tested 4 times every day for 5 days $(\mathrm{N}=20$ for each sample), consecutively at 3 levels (high, middle, and low). The coefficient of variation (CV) was calculated according to the principles of American Clinical Laboratory Standards Commission (CLSI-EP15).

\section{Statistical analysis}

Normality tests were performed using single-sample Kolmogorov-Smirnov test using SPSS17.0 for all data. Normality distribution data are reported as means \pm S.D Abnormal distribution data were logarithmically transformed for statistical analysis. The Student paired $t$-test was applied for gender-specific and age-specific group comparisons for all markers. Correlation analysis was performed using the Person method. P values $<0.05$ were considered to be significant.

\section{RESULTS}

\section{Accuracy test}

The internal quality control for all markers was at 95\%CI (Table 1).

\begin{tabular}{|c|c|c|c|c|c|}
\hline & Level & $\mathrm{N}$ & Results & Update data & $95 \% \mathrm{CI}$ \\
\hline $\mathrm{TT}_{3}$ & Low & 30 & $0.82 \pm 0.05$ & $0.81 \pm 0.08$ & $0.66-1.00$ \\
\hline \multirow[t]{2}{*}{$(\mathrm{ng} / \mathrm{mL})$} & Middle & 30 & $2.31 \pm 0.11$ & $2.28 \pm 0.18$ & $1.86-2.79$ \\
\hline & High & 30 & $4.05 \pm 0.18$ & $4.01 \pm 0.25$ & $3.22-4.84$ \\
\hline $\mathrm{TT}_{4}$ & Low & 30 & $6.08 \pm 0.32$ & $6.08 \pm 0.51$ & $4.68-7.02$ \\
\hline \multirow[t]{2}{*}{$(\mu \mathrm{g} / \mathrm{dL})$} & Middle & 30 & $12.15 \pm 0.66$ & $12.04 \pm 0.72$ & $9.43-14.10$ \\
\hline & High & 30 & $17.29 \pm 0.69$ & $17.17 \pm 1.23$ & $13.5-20.20$ \\
\hline $\mathrm{FT}_{3}$ & How & 30 & $3.92 \pm 0.16$ & $3.96 \pm 0.15$ & $3.12-4.68$ \\
\hline \multirow[t]{2}{*}{$(\mathrm{pM})$} & Middle & 30 & $9.51 \pm 0.25$ & $9.68 \pm 0.31$ & $7.78-11.70$ \\
\hline & High & 30 & $16.33 \pm 0.65$ & $16.70 \pm 0.75$ & $13.80-20.70$ \\
\hline $\mathrm{FT}_{4}$ & Low & 30 & $10.75 \pm 0.86$ & $8.45 \pm 0.75$ & $9.12-13.70$ \\
\hline \multirow[t]{2}{*}{$(\mathrm{pM})$} & Middle & 30 & $25.59 \pm 1.29$ & $20.79 \pm 1.42$ & $22.20-33.40$ \\
\hline & High & 30 & $50.22 \pm 2.73$ & $40.04 \pm 3.08$ & $43.00-64.60$ \\
\hline \multirow{3}{*}{$\begin{array}{l}\text { TSH } \\
(\mu \mathrm{IU} / \mathrm{mL})\end{array}$} & Low & 30 & $0.42 \pm 0.02$ & $0.48 \pm 0.05$ & $0.36-0.53$ \\
\hline & Middle & 30 & $5.65 \pm 0.20$ & $6.76 \pm 0.85$ & $4.83-7.25$ \\
\hline & High & 30 & $37.07 \pm 1.51$ & $42.67 \pm 5.32$ & $30.00-45.00$ \\
\hline
\end{tabular}

Data are reported as means $\pm \mathrm{SD}$. 


\section{Precision test}

The batch CV for all markers from the mixed serum samples were compared with the data provided by the kit (Table 2 ). All results were within the standard ranges recognized by our laboratory.

\begin{tabular}{llccc}
\multicolumn{6}{l}{ Table 2. Results of precision test $(\mathrm{N}=20)$. } \\
\hline \multicolumn{7}{c}{ Level } & CV (\%) & CV by the kit (\%) & CV of the lab (\%) \\
\hline $\mathrm{TT}_{3}$ & Low & 3.77 & 3.18 & 6.00 \\
& Middle & 4.08 & 2.04 & 6.00 \\
$\mathrm{TT}_{4}$ & High & 1.69 & 1.45 & 6.00 \\
& Low & 5.81 & 4.57 & 6.00 \\
& Middle & 4.96 & 1.19 & 6.00 \\
$\mathrm{FT}_{3}$ & High & 5.53 & 2.90 & 6.00 \\
& Low & 2.52 & 3.08 & 6.00 \\
& Middle & 1.58 & 2.35 & 6.00 \\
$\mathrm{FT}_{4}$ & High & 5.57 & 2.47 & 6.00 \\
& Low & 5.23 & 3.33 & 6.00 \\
$\mathrm{TSH}$ & Middle & 1.75 & 2.23 & 6.00 \\
& High & 3.51 & 2.54 & 6.00 \\
& Low & 2.26 & 2.51 & 6.00 \\
& Middle & 1.37 & 1.87 & 6.00 \\
\hline
\end{tabular}

$\overline{\mathrm{CV}}=$ coefficient of variation.

\section{Thyroid hormones}

All variables showed normal distribution, except TSH. The data for TSH were logarithmically transformed for statistical analysis. The significant differences between the gender-specific groups were observed for all markers, except TSH (Table 3). When compared between age-specific groups, significant differences were shown between group 1 and group 4 of $\mathrm{TT}_{3}$, and between group 1 and group 2 of $\mathrm{FT}_{3}$, but not between other groups of all markers (Table 4). Correlation analysis showed that not all markers were correlated with age.

Table 3. Compared results of thyroid hormones between genders.
\begin{tabular}{lcccccc} 
Gender & Number & $\begin{array}{c}\mathrm{TT}_{3} \\
(\mathrm{ng} / \mathrm{mL})\end{array}$ & $\begin{array}{c}\mathrm{TT}_{4} \\
(\mu \mathrm{g} / \mathrm{dL})\end{array}$ & $\begin{array}{c}\mathrm{FT}_{3} \\
(\mathrm{pM})\end{array}$ & $\begin{array}{c}\mathrm{FT}_{4} \\
(\mathrm{pM})\end{array}$ & $\begin{array}{c}\mathrm{TSH} \\
(\mu \mathrm{IU} / \mathrm{mL})\end{array}$ \\
\hline Male & 94 & $1.09 \pm 0.19$ & $8.86 \pm 1.44$ & $4.87 \pm 0.37$ & $15.36 \pm 1.86$ & $3.04 \pm 1.95$ \\
Female & 117 & $1.02 \pm 0.13$ & $8.46 \pm 1.27$ & $4.48 \pm 0.57$ & $14.12 \pm 1.52$ & $3.63 \pm 2.69$ \\
$t$ value & 3.299 & 2.141 & 5.868 & 5.358 & -1.776 \\
P value & $<0.01$ & $<0.05$ & $<0.01$ & $<0.01$ & $>0.05$ \\
\hline
\end{tabular}

Data are reported as means $\pm \mathrm{SD}$, measured by one-way ANOVA.

Table 4. Compared results of thyroid hormones between ages.
\begin{tabular}{lcccccc}
\hline Group & Number & $\begin{array}{c}\mathrm{TT}_{3} \\
(\mathrm{ng} / \mathrm{mL})\end{array}$ & $\begin{array}{c}\mathrm{TT}_{4} \\
(\mu \mathrm{g} / \mathrm{dL})\end{array}$ & $\begin{array}{c}\mathrm{FT}_{3} \\
(\mathrm{pM})\end{array}$ & $\begin{array}{c}\mathrm{FT}_{4} \\
(\mathrm{pM})\end{array}$ & $\begin{array}{c}\mathrm{TSH} \\
(\mu \mathrm{IU} / \mathrm{mL})\end{array}$ \\
\hline Group 1 (age $\leq 25$ years) & 22 & $0.99 \pm 0.11$ & $8.68 \pm 0.96$ & $4.47 \pm 0.76$ & $14.70 \pm 1.83$ & $3.74 \pm 1.46$ \\
Group 2 (age 26-35 years) & 76 & $1.05 \pm 0.13$ & $8.56 \pm 1.39$ & $4.72 \pm 0.57 *$ & $14.82 \pm 1.76$ & $3.46 \pm 2.11$ \\
Group 3 (age 36-45 years) & 68 & $1.05 \pm 0.17$ & $8.68 \pm 1.36$ & $4.65 \pm 0.42$ & $14.57 \pm 1.76$ & $2.90 \pm 2.88$ \\
Group 4 (age $\geq 46$ years) & 45 & $1.09 \pm 0.21^{*}$ & $8.70 \pm 1.51$ & $4.63 \pm 0.46$ & $14.56 \pm 1.88$ & $3.73 \pm 2.39$ \\
F value & & 1.877 & 0.136 & 1.420 & 0.310 & 1.420 \\
P value & & $<0.05$ & $>0.05$ & $<0.05$ & $>0.05$ & $>0.05$ \\
\hline
\end{tabular}

Data are reported as means \pm SD. $* \mathrm{P}<0.05 v s$ group 1. 


\section{Setting the reference range for thyroid hormones}

We found differences in the reference ranges for thyroid hormones obtained by us and between our results and the manufacturer's descriptions (Table 5). This indicates that separate reference ranges should be established by each laboratory.

Table 5. Thyroid hormone reference intervals $\left(\mathrm{P}_{2.5}-\mathrm{P}_{97.5}\right)$.
\begin{tabular}{lccccc}
\hline Reference interval & $\begin{array}{c}\mathrm{TT}_{3} \\
(\mathrm{ng} / \mathrm{mL})\end{array}$ & $\begin{array}{c}\mathrm{TT}_{4} \\
(\mu \mathrm{g} / \mathrm{dL})\end{array}$ & $\begin{array}{c}\mathrm{FT}_{3} \\
(\mathrm{pM})\end{array}$ & $\begin{array}{c}\mathrm{FT}_{4} \\
(\mathrm{pM})\end{array}$ & $\begin{array}{c}\mathrm{TSH} \\
(\mu \mathrm{IU} / \mathrm{mL})\end{array}$ \\
\hline This study & $0.76-1.38$ & $5.96-11.27$ & $3.88-5.59$ & $11.69-18.84$ & $0.89-5.93$ \\
Manufacturer & $0.61-1.81$ & $4.50-10.90$ & $3.50-6.50$ & $11.50-22.70$ & $0.55-4.78$ \\
\hline
\end{tabular}

\section{DISCUSSION}

Determination of the thyroid hormones is the primary method of diagnosis of thyroid diseases. Although the importance of reliable reference intervals is well understood, the establishment of reliable reference intervals for biomarkers has not always maintained pace with technological advancements. We tried to set up thyroid hormone reference intervals for samples from Zhengzhou by using well-established exclusion criteria according to the NACB (Baloch et al., 2003).

Some studies suggested that elevated levels of thyroid autoimmunity antibodies (TPOAb and $\mathrm{TgAb}$ ) and abnormal findings on thyroid ultrasound increased the risk of thyroid dysfunction, and affected the thyroid hormone reference intervals (Jensen et al., 2004; Eskelinen et al., 2005; Kratzsch et al., 2005; Hamilton et al., 2008). Therefore, we excluded individuals with laboratory evidence of thyroid autoimmunity antibodies and abnormal findings on thyroid ultrasound, including those who had consumed medicines that could affect the detection of thyroid hormones in vivo or in vitro.

In our study, $5.33 \%$ subjects were seropositive to TPOAb, 3.56\% were seropositive to $\mathrm{TgAb}$, and $2.67 \%$ were seropositive to both (data not shown) in the normal population. It was lower than the values in other published reports. For example, the TPOAb- and TgAb-positive rates were 12.1 and $10.3 \%$, respectively, in Hong Kong (Quinn et al., 2009). This could be because we tested antibody levels only for subjects with a normal thyroid ultrasound.

In this study, we investigated the association between gender and thyroid hormones. There were significant differences between men and women for all markers, except TSH. The findings are similar to those of a previous study (Quinn et al., 2009), but in contrast to those obtained by Vadiveloo et al. (2013). Despite this, the magnitude of significant differences was small, suggesting that gender-specific reference intervals are not necessary. No statistically significant difference was observed between the age groups for TSH. Correlation analysis showed that not all markers correlate with age and this is similar to the findings obtained by Jensen et al. (2004) and Schalin-Jäntti et al. (2011). In contrast, some previous studies reported that the median and range of TSH concentration increase with age (Boucai and Surks, 2009; Surks and Boucai, 2010; Kahapola-Arachchige et al., 2012; Vadiveloo et al., 2013). The differences can be attributed to the different characteristics of subjects included in the study. All markers obtained narrower reference intervals than those provided by the manufacturer, except TSH. The upper limit value for TSH was higher than that obtained in previous studies. 
Discrepancies arise because laboratories use different analyzers and populations to establish reference intervals. Therefore, it is necessary for each clinical laboratory to establish its own local reference intervals for the clinician to avoid missed diagnosis and unnecessary treatment.

Reliable and comparable results can be achieved only by conducting long-term interlaboratory studies of the analytical methods used, in terms of precision and accuracy (Solberg and Stamm, 1991). ADVIA Centaur XP analyzer was assessed for accuracy and precision; thus, the findings of the study are true and reliable.

Our study is limited by the lack of data concerning pregnant women and children (Soldin et al., 2010; Karakosta et al., 2011). Another important limitation is the assumption of iodine sufficiency in Zhengzhou area, as we did not evaluate iodine status by urine iodine estimation. However, in 2011, it was reported that the overall iodine level of the vulnerable population in Henan was appropriate (Yang et al., 2013). This indicates that, at present, the Zhengzhou area of Henan Province may be considered as an iodine-sufficient study area.

In conclusion, we added a new database of reference intervals for the serum thyroid hormones for Chinese adults. These reference intervals should be useful to interpret the results of thyroid function tests in this population.

\section{REFERENCES}

Baloch Z, Carayon P, Conte-Devolx B, Demers LM, et al. (2003). Laboratory medicine practice guidelines. Laboratory support for the diagnosis and monitoring of thyroid disease. Thyroid 13: 3-126.

Boucai L and Surks MI (2009). Reference limits of serum TSH and free T4 are significantly influenced by race and age in an urban outpatient medical practice. Clin. Endocrinol. 70: 788-793.

Chan AO, Iu YP and Shek CC (2011). The reference interval of thyroid-stimulating hormone in Hong Kong Chinese. $J$. Clin. Pathol. 64: 433-436.

Dayan CM (2001). Interpretation of thyroid function tests. Lancet 357: 619-624.

Eskelinen S, Suominen P, Vahlberg T, Lopponen M, et al. (2005). The effect of thyroid antibody positivity on reference intervals for thyroid stimulating hormone (TSH) and free thyroxine (FT4) in an aged population. Clin. Chem. Lab. Med. 43: 1380-1385.

Hamilton TE, Davis S, Onstad L and Kopecky KJ (2008). Thyrotropin levels in a population with no clinical, autoantibody, or ultrasonographic evidence of thyroid disease: implications for the diagnosis of subclinical hypothyroidism. J. Clin. Endocrinol. Metab. 93: 1224-1230.

Jensen E, Hyltoft PP, Blaabjerg O, Hansen PS, et al. (2004). Establishment of a serum thyroid stimulating hormone (TSH) reference interval in healthy adults. The importance of environmental factors, including thyroid antibodies. Clin. Chem. Lab. Med. 42: 824-832.

Jones G and Barker A (2008). Reference intervals. Clin. Biochem. Rev. 29 (Suppl 1): S93-S97.

Kahapola-Arachchige KM, Hadlow N, Wardrop R, Lim EM, et al. (2012). Age-specific TSH reference ranges have minimal impact on the diagnosis of thyroid dysfunction. Clin. Endocrinol. 77: 773-779.

Karakosta P, Chatzi L, Bagkeris E, Daraki V, et al. (2011). First- and second-trimester reference intervals for thyroid hormones during pregnancy in "Rhea" Mother-Child Cohort, Crete, Greece. J. Thyroid Res. 2011: 490783.

Kratzsch J, Fiedler GM, Leichtle A, Brugel M, et al. (2005). New reference intervals for thyrotropin and thyroid hormones based on National Academy of Clinical Biochemistry criteria and regular ultrasonography of the thyroid. Clin. Chem. 51: $1480-1486$.

Quinn FA, Tam MC, Wong PT, Poon PK, et al. (2009). Thyroid autoimmunity and thyroid hormone reference intervals in apparently healthy Chinese adults. Clin. Chim. Acta 405: 156-159.

Schalin-Jäntti C, Tanner P, Välimäki MJ and Hämäläinen E (2011). Serum TSH reference interval in healthy Finnish adults using the Abbott Architect 2000i Analyzer. Scand. J. Clin. Lab. Invest. 71: 344-349.

Solberg HE and Stamm D (1991). International Federation of Clinical Chemistry, Scientific Division: approved recommendation on the theory of reference values. Part 4. Control of analytical variation in the production, transfer and application of reference values. Eur. J. Clin. Chem. Clin. Biochem. 29: 531-535.

Soldin SJ, Cheng LL, Lam LY, Werner A, et al. (2010). Comparison of FT4 with log TSH on the Abbott Architect ci8200: 
Pediatric reference intervals for free thyroxine and thyroid-stimulating hormone. Clin. Chim. Acta 411: 250-252.

Surks MI and Boucai L (2010). Age- and race-based serum thyrotropin reference limits. J. Clin. Endocrinol. Metab. 95: 496-502.

Surks MI, Ortiz E, Daniels GH, Sawin CT, et al. (2004). Subclinical thyroid disease: scientific review and guidelines for diagnosis and management. JAMA 291: 228-238.

Vadiveloo T, Donnan PT, Murphy MJ and Leese GP (2013). Age- and gender-specific TSH reference intervals in people with no obvious thyroid disease in Tayside, Scotland: the Thyroid Epidemiology, Audit, and Research Study (TEARS). J. Clin. Endocrinol. Metab. 98: 1147-1153.

Yang J, Zheng HM and Chen G (2013). Iodine nutritional status of the vulnerable population in Henan province in 2011. Zhonghua Yu Fang Yi Xue Za Zhi 47: 14-17. 